\title{
JORDAN CONSERVATION of CULTURAL HERITAGE in ERA
}

\author{
A. Al Bawab a b, *, R. Abdallah a c, A. Bozeya a, F. Odeh a b, H. Al Ashqar a \\ a Hamdi Mango Center for Scientific Research, The University of Jordan, Amman, 11942, Jordan- (drabeer@ju.edu.jo, \\ haneen56@yahoo.com, a.bozeya@ju.edu.jo) \\ b Chemistry Department, The University of Jordan, Amman, 11942, Jordan- f.odeh@ju.edu.jo \\ c Institute of Archaeology, The University of Jordan, Amman, 11942, Jordan- rmdnabdalla@yahoo.com
}

\begin{abstract}
KEY WORDS: Cultural Heritage, Nanotechnology, Conservation, Capacity Building, Colloid Chemistry, HMCSR, UJ, Material Science
\end{abstract}

\begin{abstract}
:
The Jordan Conservation of Cultural Heritage in ERA - JOCHERA project is aiming at overall reinforcement of University of Jordan (UJ), Hamdi Mango Center for Scientific Research (HMCSR) in Jordan cooperation capacities for cultural heritage protection research in the context of the European Research Area and development to the Conservation centre of excellence to respond to Jordan's socio-economic needs. The JOCHERA impact will be increased capacities of the UJ in terms of (i) better research and innovation management, (ii) improved international Science \& Technology cooperation and participation in FP7, (iii) enhanced cultural heritage protection research capacities, and (v) defined strategic development framework in order to increase UJ visibility and scope. Likewise, JOCHERA will increase research and innovation linkages within Jordan in particular with SMEs, enable better opportunities to young researchers and enhance EU-JO RTD cooperation landscape. The project duration is 24 months, started in $1^{\text {st }}$ December 2011 and will end in 31 November 2013.
\end{abstract}

\section{PROJECT CONSORTIUM}

The JOCHERA consortium brings together one Jordanian and four EU organizations representing a well-defined mix of expertise for strategic development, innovation management and technological foresight.

\subsection{The University of Jordan (UJ), Jordan}

UJ is both a modern as well as old institution of Higher Education in Jordan. It was established in 1962. From an international perspective, the University offers 63 international programs at the undergraduate level, and 130 international programs at the graduate level and in all fields of specializations.

There are some research centres within the University; Hamdi Mango Centre for Scientific Research (HMCSR), Geo-Material Research Project centre, Water \& Environmental Research and Study Centre, Marine Science Station (MSS).

UJ signed a memo of understanding for setting up and operating an information focal point to participate in EU project with the name of SRTD: "Support Research and Technology Development and Innovation and Strategies in Jordan" which was a project funded from EU. The university appointed Liaison Officer for the SRTD where the main object of this project was to promote the FP7 to Jordanian researchers inside the university, as a result the number of people involved in FP7 projects increased, two of them were granted till now: L Tehealth \& EMAP (2010), also two under negotiations, while there are at least 4 other projects under evaluations (2011 \&2012).

UJ also was involved in many international projects included European projects such as; PTIMA, DIMAS, MELIA, MEDCOLOUR-TECH - Investigation, revival and optimization of traditional Mediterranean coloring technology for the conservation of the culture heritage - and SMART.

Inside the UJ there is an agriculture incubator which has produced some spin off companies such as Bee Way (Non Traditional Bee Products, To produce royal jelly, bee venom and bee queens), Timeless (Multi Cosmeceuticals, Beauty without side effects), Rosy City (Production of novelty cheese products, Tofu Cheese and Soy Milk products, Bumble Bee (Pollination services under green houses in Jordan), Amazon (Production of Enviro-plants, Environmental nursery), Specialty Meals and Diet Center (Health food product for special need people)

Hamdi Mango Centre for Scientific Research (HMCSR): HMCSR is an independent research centre unit established in 1999 inside UJ. The centre hopes to channel material and financial support for researchers dealing with scientific and technical problems of great importance and having impact into the Jordanian society. HMCSR is dedicated to the support of interdisciplinary as well as well-defined research projects in the fields of Applied Science and Technology. The centre unites scientists from various fields under one roof: e.g. physicists, chemists, biologists and engineers. HMCSR aspires to active participation in developing resources, at the University of Jordan, to conduct original research in the fields of material science, nanotechnology, biotechnology, pharmaceutical solution and drug discovery.

The main research areas are focused in nanoscience in variety of fields such as; materials chemistry, nanosynthesis, composite materials, nanostructured materials, environmental, targeted drug-delivery systems for cancer treatment, preparation of new materials for slow release of drugs from natural resources.

Some of the current research topics that are investigated inside the center: surfactant enhanced remediation of polluted water,

\footnotetext{
* Corresponding author. This is useful to know for communication with the appropriate person in cases with more than one author.
} 
targeted-delivery of macromolecular drugs for cancer cells, use of kaolinite for the synthesis of zeolites and anti-microbial zeolites, the effect of nano-sized starting powders on the physico-chemical properties of the RE123 superconducting ceramics, toxicity of Jordanian zeolitic nano tuff to the nematode, characterization and beneficiation of new-explored Jordanian zeolitic tuff from selected localities in northern, central, and southern Jordan, and investigation their capability for removal of pollutants from water. The research inside the center is coordinated within the Material Science and Nanotechnology, Biotechnology, Drug Discovery Pharmaceutical Solution laboratories.

The Material Science and Nanotechnology laboratories are divided into three Research Groups (RG): (I) The RG of Superconductors materials; where its goal is to produce superconductors from nano sized precursor via coprecipitation method (II) The RG of Colloid and surface chemistry; where its goals are to study colloidal solutions stability, and to use the phase science in a variety of problems (III) The RG of Natural geomaterials for construction and industrial applications, its goals are to investigate the Jordanian zeolitic tuff, the mineralogical, chemical characterization and the adsorption capability towards organic and inorganic pollutants.

Recently a Technology Transfer Office (TTO) was established inside the center to help researchers connecting their research into the applied zone in addition for helping in IP issues.

\subsection{Politecnico di Torino (POLITO), Italy}

POLITO represents a leading public university, in Italy and in Europe, in technical-scientific teaching and research. Founded 150 years ago, nowadays Politecnico di Torino has three Schools of Engineering, two Schools of Architecture, a School of Economics and Management, plus a Post-Graduate School. Research activities are organized in the 18 "Dipartimenti" and in 12 service centres. Furthermore, the "Dipartimenti" provide Faculties and the Schools with teaching staff.

The Politecnico is a research university interested in the balanced development of both theoretical and applied research. It has closed relationships with international institutions, companies, local government and other types of association and takes social and economic consideration into account. With more than 150 bilateral international agreements and 40 double degree agreements, POLITO has links with the most prestigious Universities in Europe. POLITO is part of some of the major European interuniversity networks, such as CESAER, CLUSTER, E.C.I.U, EUA, CMU. The participation to many international projects allows PT to count on a great experience both in project scientific and administrative management. With its involvement in 88 projects funded under FP5 and 87 projects funded under FP6, Politecnico di Torino has a strong experience in project coordination.

POLITO will participate to JOCHERA through researchers belonging to the Department of Electronics (DELEN) and the Department of Materials Science and Chemical Engineering (DISMIC). DELEN is composed of over 100 researchers in the fields of electronics, metrology and chemical measurements, wireless networks, optoelectronics, portable instruments for conservation of cultural heritage and innovative sensors for environmental monitoring, with the PhotonLab, which is an innovative laboratory for the research on high performance optical networks, components and communication systems. DELEN is involved in several national and international projects on ICT, electronics, laser technology, sensors, as High Power Laser in NANO-structured fibers, Converging Technologies 2007. DISMIC, promotes and co-ordinates teaching and fundamental and applied research activities in the following areas: materials science and technology, conservation of cultural heritage, corrosion and protections of metals, thin films deposition and plasma treatments, electrochemistry and LCA analysis. DISMIC researches are involved in several national and international projects with particular attention to the cooperation with South Mediterranean Countries: European Project Growth, FPV, NANOMAG (Development of Innovative Nanocomposites Coating for Magnesium Castings Protection 2002-2005), European Project, FP VI, MATECO (New coatings deposited by PACVD for corrosion protection 2004-2007); European Project INCO-MED, FPV, EFESTUS (Tailored strategies for the conservation and restoration of archaeological value $\mathrm{Cu}$-based artefacts from Mediterranean Countries, 20032005), European INCO-MED Project, FPVI, PROMET (Developing new analytical techniques and materials for monitoring and protecting metal artefacts and monuments from the Mediterranean country, 2004-2007); European project SSA, FPVI, MEDAL (Mediterranean conservation alliance - 20072009).

DISMIC and DELEN researchers are also involved in two ERAWIDE projects ((FP7-INCO-2010-6, ERAWIDE, Area INCO.2010-6.2): CB-WR-MED (Capacity building for Direct Water Reuse in the Mediterranean Area - 2010-2012) and PERA (Palestine for European Research Area - 2011-2013).

\subsection{Middle East Technical University (METU), Turkey}

METU is a state university, founded in 1956, currently has about 23,000 students of which 4,500 are in masters and 2,700 are in doctorate programs. METU hosts over 1,500 international students from nearly 80 different countries. METU has 40 undergraduate programs within 5 faculties. Additionally, there are 5 Graduate Schools with 97 masters and 62 doctorate programs and a "School of Foreign Languages" which includes the English Preparatory Department. The language of instruction is English. METU has $\mathbf{1 6 8}$ Erasmus agreements and 182 bilateral exchange and cooperation agreements with universities in third countries.

\subsection{Fundacion Technical Research \& Innovation (TECNALIA), Spain}

TECNALIA is the leading private research and technology entity in Spain and the 5th largest in Europe; with 1,437 staff (164 PhDs), $121 \mathrm{M} €$ turnover, 53 patents, 3800 clients and 8 spin-offs (2009 data). TECNALIA is very active in the FP7 with 150 projects funded (31 as coordinator). From 1st Jan. 2011, TECNALIA has become a research organisation resulting from the merger of 8 research organisations, including Fundación LABEIN (the team involved in this proposal), which already changed its name to TECNALIA on Sept. 2010.

TECNALIA has a wide experience in Cultural Heritage issues, mostly in Immovable Heritage. As a private research centre close to market application, it has been involved in several research projects dealing with Cultural Heritage issues, at both National and European level.

TECNALIA has expertise in developing high performance products for the construction sector using nanotechnology and has a wide range of knowledge and experience on the synthesis, fictionalization, dispersion and characterization of nanoparticles and nanocoatings. In addition, TECNALIA has developed R\&D European and national projects in the assessment of surface treatments for cultural heritage $(\mathrm{CH})$ materials, being FP6 "Graffitage" project one of the most relevant examples. Besides, TECNALIA has expertise in real assessment of commercial 
treatments on $\mathrm{CH}$ materials (mostly stone, bricks and mortars), and has performed practical work on more than 150 Spanish and Latino-American Monuments (from the Roman period to the XIX Century).

As coordinator in 3 Cultural Heritage related FP6 projects: GRAFFITAGE ("Development of a new antigraffiti system, based on traditional concepts, preventing damage of architectural heritage concepts"), OPERHA and CHRAF. In FP7, also on $\mathrm{CH}$, participation in TEACH ("Technologies and tools to prioritize Assessment and diagnosis of air pollution impact on immovable and movable Cultural Heritage") and CHIC (Cultural Heritage Identity Card) and an SME project, EFFACEUR.

Tecnalia has experience in IPR protection, patents licensing and creation of spin-offs to uptake project results into the market.

Member of the ECTP, it is participating in five of the six of the Focus Areas of the ECTP and it is coordinator of the FA Cultural Heritage. It is also participating actively in the Spanish Construction Technological Platform co-leading the Area of Cultural Heritage.

TECNALIA has undertaken a socio-economic impact analysis of Cultural Heritage related FP5-FP6 projects, and it was coordinator of the exhibition salon of the $8^{\text {th }}$ EC Conference on Sustaining Europe's Cultural Heritage.

\subsection{Rete Europea Dell'Inovazione S.r.I (REDINN), Italy}

REDINN is a European consulting company specializing in Innovation Consulting, Management Innovation and Innovation Strategy. The main aim is to accelerate growth through innovation. REDINN works in partnership with client to achieve outstanding sustainable results and implement winning innovation strategies.

With offices in Brussels and Rome and a network of partner companies over the EU countries, REDINN operates on many levels (Technology Audit, IPR, Technology Transfer, start up and SME acceleration). The services it offers are legibility assessment for Innovative products and process, the creative development of international and EU funding roadmaps, project ideas, project definition, planning, structuring and design, preparation of funding proposals.

The main activities are focused on three main areas of expertise: 1. Innovation policies and RTD studies;

2. Project management for Innovation and RTD related projects; 3. Consultancy services.

\section{CONSORTIUM AS A WHOLE}

The consortium represents a well-defined mix of competencies and expertise in the cultural heritage research sector in particular material science, to ensure successful project implementation and achievement of objectives by means of strengthening of cooperation capacities and research activities The Jordanian partner will be in charge for overall project coordination and provision of know-how on technology of conservation of cultural heritage research sector, main actors and priorities in Jordan, while EU partners are responsible to provide access to EU networks and support capacity building of research centres. Critical mass for sufficient momentum to ensure self-sustainment and further development is achieved by comprising key complementarities between project partners.

The five partners will act complementarily towards the implementation of the project's objectives, through the following domains:

\subsection{The Nature of the Activities}

The consortium developed around three universities (UJ, POLITO, and METU) one SME (REDINN) and Research and Innovation Centre (TECNALIA). The activity of the partners covers the two objectives of reinforcement capacities in the fields of (i) EU-Jordan cooperation and (ii) S\&T research qualities on related conservation of cultural heritage project topic. The consortium offers expertise and consultancy on applied research and international cooperation.

\subsection{The Domains of Activities}

In environmental monitoring, non destructive diagnostic tools, material science, and nanotechnology in art conservation. The whole grouping of these domains of activity shares the common theme of innovative technologies for painting wood conservation cleaning artworks, wall painting stones and metal artefacts conservation.

\subsection{The Geographic Distribution}

The partners of the project are from 4 Mediterranean countries (Italy, Spain, Turkey and Jordan).

\subsection{The Equipment and the Used Tools}

The consortium is well equipped on training, experimental analytical, monitoring, software and multimedia tools.

UJ has solid expertise in material research and proficiency in fostering sustainable international R\&D cooperation through creation of partnerships and participation in various projects. Having experience in EU-funded projects, UJ takes a position of project coordinator. EU partners are $\mathrm{R} \& \mathrm{D}$ and innovationfocused organizations. Respectively POLITO, METU, REDINN and TECNALIA that are situated extensively within international networks, have rich experience in FP programs, capacity building, know-how and technology transfer. POLITO and TECNALIA have extensive in material science, electronic measurements and non-destructive diagnostic techniques research capacities and strong links to nanotechnology, ICT and material science research sector stakeholders within the EU, and therefore will provide a gateway for internationalization of Jordan conservation and cultural research centres. REDINN, TECNALIA, have outstanding expertise in the FP7 training, mentoring and coaching activities and will support capacity building of material science research actors in Jordan

\section{PROJECT OBJECTIVES}

The overall objective of JOCHERA project is the reinforcement of University of Jordan's cooperation capacities for cultural heritage research in the context of the European Research Area and development to the Conservation centre of excellence to respond to Jordan's cultural and socio-economic needs.

The specific objectives of JOCHERA project are:

- Better Coordination Between Policy, Research and Business in Jordan

- Enabling Better Participation in Framework Program

- Enhancement of EU-JO S\&T Partnerships in Cultural heritage conservation

- Capacity Building for Solving Specific conservation problems and developing tailored conservation strategies 
- UJ's Strengthening and Cooperation Capacities Reinforcement Establishment of a EU-JO conservation alliance and Results Dissemination

The reinforcement of the cooperation with Europe's neighbours in the context of of the European Research Area (ERA) is an important part of the EU Commission communication on the Strategic Framework for international S\&T cooperation. This should complement the Research and Innovation activities described in the National Indicative Programs and covered by the European Neighborhood and Partnership Instruments (ENPI).

The improvement of international cooperation in research will create better conditions allowing research entities in Jordan, public or private, to better exploit and expand their research potential, thereby contribute to regional development by benefiting from the knowledge and experience in the EU and in associate member countries. Additionally, this project will also help to the neighboring countries in terms of their integration to the ERA. By focusing on the enhancement of the quality of the conducted scientific research in the selected research entities and by encouraging collaboration between partners and excellent research entities elsewhere in the EU, this project will contribute to the setting-up of strategic partnerships through FP7 project. Hence, this project will enable the Jordan partners to realize their full potential. This project will also help in reaching sustainable development and creation

\section{OVERALL STRATEGY OF THE PROJECT}

According to the Capacities - Work Program addressing ERAWIDE, highest priority is given to strengthening and reinforcement of the cooperation capacities of research centres located in the ENP countries, which are not associated to FP7. The strengthening includes first of all Twinning with research centres in Member State/Associated countries, Training Activities, Capacity building Activities and also research centre's strategy activities. The JOCHERA will establish and implement a framework to reinforce the cooperation capacities and research activities in Jordan's Cultural Heritage protection sector by defining cultural heritage research priorities to respond to socio-economic needs, facilitating participation in European cultural heritage research initiatives and development of strategy for research centre based on thorough analysis of current situation, cooperation patterns, relevant actors, needs and opportunities.

In order to ensure a coherent and well-organised structure and implementation of the project JOCHERA consists of five work packages $(W P)$. Every work package is under the responsibility of one WP leader. The work packages are subdivided into a number of tasks and subtasks, which are in turn related to concrete activities and deliverables. Each task will be organised by a task leader and executed with the help of the consortium partners attributed to the task. Every task in the work package will be handled with a significant degree of autonomy by the task leader. The work of the task leaders is crucial to the project since they will be responsible for the organization of the work in the task and for the preparation of the deliverables in time and in good quality. The task leaders will report to the respective work package leaders.

\section{EXPECTED IMPACT}

The JOCHERA Partnership will contribute to a systematic exchange of information, experience and best practice in order to establish comparable principles and standardised processes for joint multilateral activities. Additionally, harmonised IPR regulations, evaluation standards, jointly elaborated training courses, will be established to run possible future co-executed multilateral activities. The impact of JOCHERA is expected to be felt in the international sphere. Through the implementation of Work packages, the construction of a fully operational European Research Area on tangible cultural heritage preservation will be fortified and enlarged

JOCHERA will produce cooperation and support resulting in:

- Streamlining the capacity of UJ to coordinate its activities with European partners, and to actively participate in Framework Program activities. The project will address the strategy plan required to increase institutional visibility and RTD excellence at National, Regional and International levels.

- Fostering the capacity of European partners to cooperate with Jordan research institutions. The FP7 workshops and the other international events will permit to bring together local, Mediterranean and European institutions and public/private enterprises. These events represent the opportunity to present UJ organization to external potential partners for future joint research projects and cooperation activities.

- Integration with other FP7 project in the Region. As foreseen in WP1, twinning with other EU ERA-WIDE Project as well as with project funded by other donors, will be establish. This activity will be aimed to exchange information and/or perform common activities exploring the possibility to organize joint networking, dissemination events). In this way JOCHERA will permit to establish synergic effects

\section{THE PROJECT ACTIVITIES}

The JOCHERA activities are designed in order to reinforce the local capacity building for the participation in EU Framework Programme and to reach relevant impact on the increasing cultural heritage sector in Jordan.

The project will offer several capacity building opportunities using different tools in order to support UJ with all the necessary expertise it needs to became a competitive research centre with an Euro-Mediterranean vision and a wellestablished regional position

\subsection{Study Visits}

The study visits with the aim to increase the scientific collaboration between UJ and POLITO and UJ and METU through the exchange of knowledge and good practices.

6.1.1 First Study Visit, 28th March 2012: The first study tour in the project at the POLITO was for two employees of the UJ: Prof. Abeer Al Bawab (project coordinator), and Dr. Fadwa Odeh (researcher).The event was planned for three days and focused on exchange of knowledge and experiences in organization of research process. Prof. Al Bawab gave presentation about the history and culture in Jordan and the specific needs in the field of conservation of cultural heritage in Jordan. While Dr. Odeh, gave a summary of the projects that was conducted in Jordan in the field of conservation of cultural heritage and the methods used in conservation. A statement of collaboration describing the research directions and activities for exchange knowledge between the two partners was determined at the end of the tour. 


\subsection{FP7 Capacity Building Workshop and One to One Sessions}

Innovative training workshops and one to one sessions will be foreseen into the project with the aim to offer to Jordan researchers the opportunity to experiment themselves in proposal writing and EU project management. Such events will empower the capability of UJ researchers and key personnel in check FP7 funding as well as other relevant EU funding opportunities, make trial on practical exercises based on successful projects as best practice examples, proposal writing exercises, practical and financial management of EU projects

6.2.1 First Training and Coaching Sessions 4-5 June 2012: The First training, aiming to explain the EU's Seventh Framework Programme for Research and Technological Development (FP7) and prepare to apply projects under upcoming calls for proposals.

FP7 Programme is the largest research programme supporting European and international research cooperation.

The next call for proposals will be announced 12th July 2012 with application deadlines in the autumn 2012 and in spring 2013.

FP7 is a very competitive programme, which offers large scale of participation opportunities, but also a very challenging competition.

Therefore submission of comprehensive and competitive high quality proposals is a necessity for being successful in this competitive environment. Researchers, who are developing proposals for the programme, need specific set of knowledge and skills, which JOCHERA project and this FP7 training is aiming at. The JOCHERA first training programme:

- Provide background knowledge about the European research funding system

- Train practical skills on how to develop a competitive proposal

- Offer continuous coaching support with guidance towards project collaborations and

- supporting the participation in FP7

\subsection{Symposium}

The aim of the symposium was to gather the academics, researchers, experts in cultural heritage conservation in order to discuss and analyze the current situation in Jordan and explore new ways of collaboration both at national and European level. The seminar's results will be collected in the Jordan's Cultural Heritage Symposium (JCHS) then a report, which will include the output of this symposium, case studies and best practices in Cultural Heritage conservation.

6.3.1 Conservation of Cultural Heritage in Jordan Symposium $6^{\text {th }}$ June 2012: UJ/ HMCSR organized symposium entitled "Conservation of Cultural Heritage in Jordan, the symposium hosted many lectures and presentations. The participant in the symposium included a group of Jordanian and European researcher with interest in various approaches and aspect of cultural heritage preservation, and group of Jordanian governmental and nongovernmental policy maker of cultural heritage. The presentations varied from setting conservation and restoration laboratories, the global cultural sites in Jordan and the international standard for its conservation, innovation in cultural heritage, the monitoring sensors of temperature and humidity used in museums, to challenges facing the archaeology in Jordan,

Some of the listed speakers were:
The Director of the Centre, Prof. Abeer AL Bawab, pointed out that the cooperation with these partners allows UJ to benefit from the exchange of research and administrative experiences, strengthen its competitiveness and impact on scientific and applied research in the future by joint projects in the field of cultural heritage conservation in Jordan. Also, she listed some research projects relating to the cultural heritage conservation under the umbrella of FP7 that had been implemented over the past years. Emphasizing there is an urgent need to create a comprehensive database of these projects, analyzing the main objectives and the outcoming of these projects, to find out the cross section among them to avoid duplication, and finally to get some benefits from them. As a result a well defined road map will be available for the young researchers, enabling them to add missing fields and to create new projects in the field of cultural heritage protection.

Mr. Leonardo Piccinetti, the director of REDINN presented FP7 Capacities Programme - International Cooperation Activities ERA WIDE the presentation was with two aims first to compete nationally and internationally to attract the best teachers, researchers and students, second to compete for financial resources for research and infrastructure, as well as for contracts with business sector. Mr. Piccinetti also pointed out that there is an urgent need for a greater linkage and dialogue in the policy development of the European Higher Education Area (EHEA) and the European Research Area (ERA), particularly in relation to achieving a sufficient flow and supply of competent researchers. It is essential to ensure maximum synergies between the "Bologna Process" in building the EHEA and the parallel development of the ERA - "Viewed together, EU support through the Research Framework Program and the wider Bologna process represent a major investment in Europe's education, training and research sector to meet the Lisbon and Barcelona goals, notably in combating the present lack of qualified manpower.

Dr. Raghda kilani as the national contact point at the European Union presented an overview on the status of scientific research about science, technology and innovation in Jordan in addition to the local and international supports of the European Union. The Dean of the Institute of Archaeology at UJ, Dr. Nabil Khairi, presented coins extracted from Petra that have been maintained and restored in the Institute laboratories under the supervision of the Head of Department of Cultural Resources at the Institute, Dr. Ramadan Abdullah.

The represented of the Heritage Committee of UNESCO in Jordan, Prof. Moawiyah Ibraheem talked about the challenges facing archaeological sites in Jordan such as urbanization at the archaeological sites and the increase number of tourists. Also he pointed out the need of developing a new strategy by experts in the area of cultural heritage protection in order to preserve the archaeological sites through raising the public awareness along with an emphasis in the nature of the laws and regulations that protect these sites.

Dr. Naima AL Husban from UNESCO in Jordan stated that the Organization's role in the protection of natural and cultural heritage is an essential part. Also, it will support projects that seek to preserve the heritage according to the global standards. Dr. Alessandra Gandini from Fundacion Tecnalia Research \& Innovation in Spain focused on conserving the Archaeological sites in the centre through the third International Exhibition for Spanish Archaeological sites conservation. Also, she talked about the centre's projects in the field of archaeological sites conservation.

The Secretary of Umm Qais Archaeological Museum in Jordan, Mr. Nasr Al-Zoubi tackled the Conservation and treatment of inorganic that were found from Umm Qais archaeological site, 
Northern Jordan in 2009. Moreover, he pointed out that special materials have been used in conserving and protecting those according to the international standards and they has been saved in the museum warehouse in spite of the lack of, monitoring and controlling equipments.

Dr. Wasef Hawari from Yarmouk University expressed his worries about the way of dislocating mosaic floors discovered by the researchers during the process of archaeological excavations that affect negatively in terms of aesthetic, archaeological and cultural levels. He demands the need of the preservation the archaeological and aesthetic character of the mosaic floors through conserving and protecting them.

The most achievements of the symposium were:

- The gathering of Jordanian researchers interested in cultural heritage and their interaction with their European counterparts.

- The networking among Jordanian researchers themselves was initiated. Various points have been agreed upon as the outcomes of this symposium, these include

$\checkmark$ Constructing of a database for all researchers in the field of cultural heritage conservation in Jordan, and the symposium attendees can be considered as the seed for this database

$\checkmark$ Constructing of a database of all international and national projects in the field of cultural heritage conservation in Jordan that were performed in the past \{ the establishing of database, a technical glossary (techniques, materials and typologies) from the successive programs and projects covering cultural heritage research in Jordan, where the participants agreed at the importance of collecting all the results from the finished works that were concerning in cultural heritage in Jordan to get benefit from it and to complete the needs in preserving our heritage and improving our environment

$\checkmark \quad$ Evaluating the outcomes of these projects in order to better direct and plan ongoing and future projects concerned with cultural heritage conservation in Jordan

- Strengthen interaction and collaborative research between Jordanian and European researchers, universities, institutes and centers in the field of cultural heritage conservation in Jordan

- Introduce students (both graduate and undergraduate) to research in the area of cultural heritage conservation in Jordan and the various sciences that play a role in such a vast research area

- Proposing and recognizing some solutions for the potential, lacks and needs of governmental and nongovernmental sectors in Jordan dealing with cultural heritage and their implementation for the development of cultural heritage rational management and dissemination strategies and tools, and improvement of the conservation system in Jordan, to achieve a firm commitment to an integrated conservation strategy that balances the needs of various stakeholder.

\subsection{Final conference}

Final conference to represent project results, and, in particular, Cultural Heritage Conservation priorities for Jordan, will be organized in Amman by University of Jordan (HMCSR). Researchers, experts in Cultural Heritage conservation, cultural stakeholders will be invited to meet high-level EU representatives, policy makers, National Contact Points and successful project coordinators. The event will be extensively promoted and transmitted through various media channels (electronic, print and broadcast) within and outside of the Jordan.

\section{REFERENCES}

References from websites:

www.jochera.eu

\section{ACKNOWLEDGEMENTS}

Project Funded by the European Commission under the $7^{\text {th }}$ European Framework Programme - Activities for International Cooperation of the Capacities Programme (JOCHERA, 294975, Jordan Conservation of Cultural Heritage in ERA, Prof. Abeer Al Bawab, UJ/HMCSR).

\section{FURTHER INFORMATION}

If you have questions about the submitted paper, please contact the corresponding author drabeer@ju.edu.jo 